\title{
Communication and connectivity as veritable tools for information sharing in Nigeria
}

\author{
Mamudu Friday, Mustapha Ismail
}

Department of Mathematics, Gombe State University, P.M.B 127 Tudun Wada, Gomb
This paper discusses the contributions of communication technologiss globalization and the role of connectivity as facilitator to efficient globa ${ }^{1}$ nIvima sharin today. The background study of networks, satellites, statement of the problem a ne objectiv nere looked into. A brief historical development of Nigeria communic? ons their bene, cial applications today were presented. Presentation was made on why internet vinunica in Nigeria is dominated by wireless/satellite link. It was adduced that the absenc of iniormation anology infrastructure, particularly the complete absence of fiber optics backb he and weak telecommunication base were responsible for the predominant wireless internet applicat in Nigeria. The paper concludes that a good information technology infrastructure base such as the truction domestic optics backbone as ongoing by some of the GSM operators sur as Globa MTN, launching of domestic communication satellite such as Nigcomsat1 communication will enhance information sharing and s. Feduce the cost of internet applications and motivate a larger population to participate in o new in ormation society.

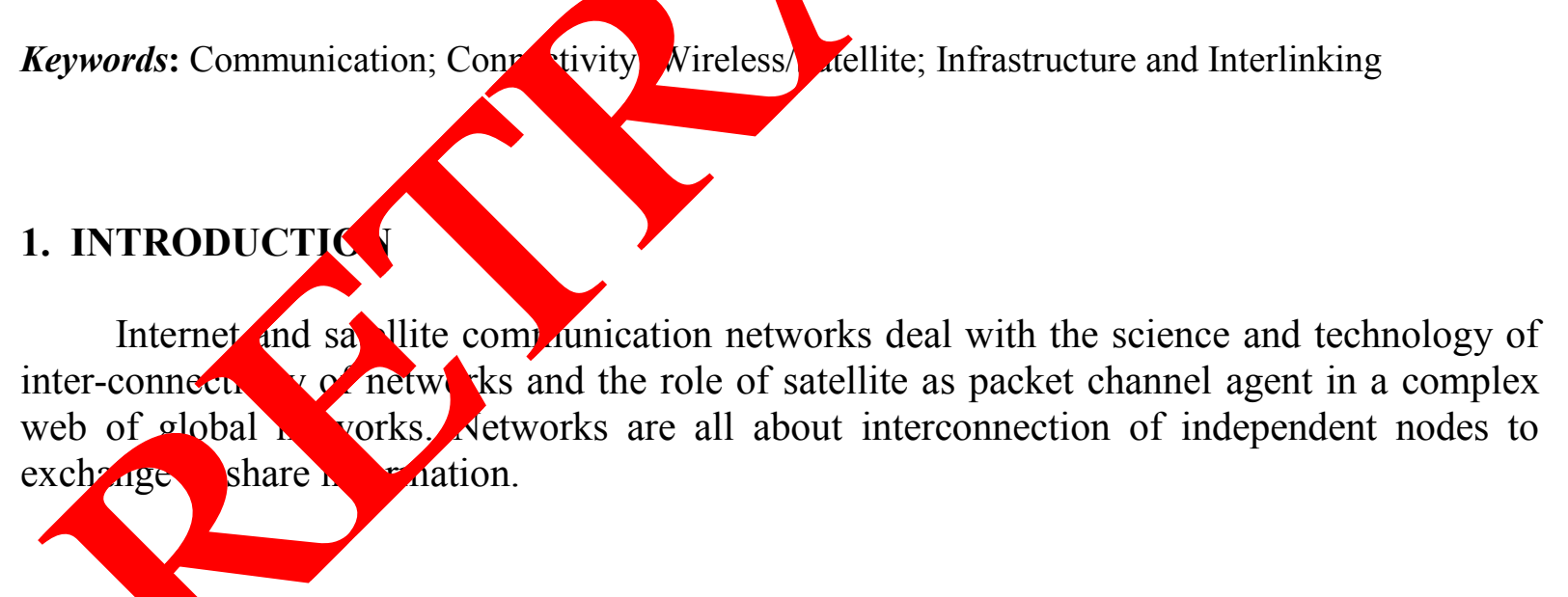

\section{THE TERNET}

Information Technology (IT) is the convergence of micro-electronics telecommunications and computer technology. This explains UNESCO'S definition, which states that IT is "the scientific, technological and engineering disciplines and the management technologies used in information handling and process, their application, computers and their interaction with man, machines and associated socio-economic and cultural matters". The computer networks have become so developed that they span the entire globes. The convergence of computer technology and telecommunications has necessitated the need to 
research for international open standards that could make possible for dissimilar networks and topologies to link and share information without hiccups.

An article concludes that "( the internet) has become a mass medium used most by relatively passive consumers, and as such major content providers" ( Margolis and Resnick, 1999). The book (Winston, 1998) also presents the internet as the next step in the evolution of mass media.

\section{THE SATELLITE}

According to Osuagwu (2002), a satellite can be defined as a powerful $r$ transmit with transponders positioned aerodynamically in the orbit at $36,000 \mathrm{ft}$ above sea vel. Th amplify, sort or route signals. Unlike wireless ground repeaters which clay signa etw en two fixed locations; satellite interconnect many locations, both fixed a mo oyer wide area. It receives microwave signals from equipment on the earth a frequ by band (uplink) and re-transmits them at a different frequency to earth s ations (do link)

A satell anythi of that orbits something else just as the moon orbits the earth. Howey sateh is a pecialized wireless transmitter/receiver that is launched by a rocket and place in orbi cound the earth. Satellite can be used either for security, weather foro tin dentify mineral deposits, television broadcast, amateur radio communications, interno Tmmuncations, global positioning system (GPS), Motor vehicle tracking system, e.t.c.

Ther are three major categories of satellite systems namely:

(i) A geostationary satellite - which orbits the Earth directly over the equator, approximately 22,000 miles up. It then takes 24 hours to make one complete revolution around the earth. Hence, it remains at the same spot on the earth's surface at all times, and stays in the sky from any point on the surface from which it can be "seen". E.g. weather satellites are in this category. Images can be viewed from these satellites on the internet via the Purdue weather processor. One of these satellites can view approximately $40 \%$ of the earth's surface and such three of it can view the whole world. 
(ii) A low-earth orbit (LEO) - satellite system employs a large fleet of "birds," each in a circular orbit at a constant altitude of a few hundred miles. Each revolution takes approximately 90 minutes to a few hours. The fleet is arranged in such a way that, from any point on the surface at any time, at least one satellite is on a line of sight. In this type of satellite, the transponders are moving rather than being fixed, and are in space rather than on the earth. The good thing about this satellite is that it makes it possible for anyone to access the internet via wireless from any point on the planet using an antenna.

(iii) Elliptical orbit satellite system - revolve around the earth in elliptical orbits. These satellites move rapidly when they are in their lowest altitude and slowly when they are in th altitude. Such satellites are used by amateur radio operators, and by some co nmercial government services. They require directional antennas whose orientation mas constan adjusted to follow the satellite's path across the sky. (Prince, 2011).

\section{STATEMENT OF T E P BLEM}

The preser communica 1 etwork in Nigeria is poised with a lot of problem such as network faily when a caller and the receiver cannot hear each other at times while the caller's crean ing ded ted.

Thes $1 \mathrm{~m}$ nse pry hes (SMS) sent were not delivered but the sender is being charged.
in atio in Niger communication system so that the network user will not be disappointed and lo ommum in the ability of the service provider whenever they make call.

\section{OBJECTIY $\angle S$}

(i) To ascertain how wireless internet, satellite and fiber optics are tools for information sharing;

(ii) To determine the effect and the best tool for information sharing;

(iii) To make projections for the future role of internet, satellite and fiber optics. 


\section{BRIEF HISTORICAL DEVELOPMENT OF COMMUNICATION IN NIGERIA}

Telecommunications facilities in Nigeria were first established by the colonial administration. At independence in 1960, with a population of about 40 million people, Nigeria had only about 18,724 telephone lines for use which translated to teledensity of about $0.5 \%$ telephone lines per 1000 people. The telephone network consisted of 121 exchanges of which 116 were the manual (magneto) type and only 5 were automatic type.

Between 1960 and 1985, the telecommunication sector consisting of the department of posts and telecommunications $(\mathrm{P} \& \mathrm{~T})$ limited in charge of internal network and, the Nigerian external telecommunications (NET) limited, responsible for the external telecomm ins services provided the gateway to the outside world. The install switching capacit at the en $f$ 1985 was about 200,000 lines as against the planned target of about 460,000 es. All t exchanges were analogue. Telephone penetration remained poor as one te hono to 10 inhabitants was recommended by international telephone union (ITU) fo deve ping on The equality of service was largely unsatisfactory, unreliable, consted and and customer unfriendly.

Arising from the foregoing, in January 1985, the erstwhil osts and to op munications department was split into postal and telecommunications li itec UTEL), a imited liability company. The main objective of establishing NITEL wa to harmo the planning and coordination of the internal and external telecommanications deve sment, and provide
accessible, efficient and affordable services.

Forty six years ago after independence, the $\mathrm{N}$ eria telecol imunication PLC (NITEL); had roughly half a million lines available to over 120 "lion Ni gerians. NITEL, the then only national carrier, had a monopoly on the or, and synonymous with epileptic and unreliable services and poor management. O ass tion of office on the $29^{\text {th }}$ of May, 1999; former president Olusegun Obasanjo's admi is ation swung to gear to make a reality, the complete deregulation of the tele unicat ns sectors, most especially, the much touted granting of licenses to GSM ser ce pr iders an setting in motion the privatization of NITEL. Also, this administration imse el nigerian Communication Commission (NCC) with new br of protessionals in the telecommunication industry. The commission duly orga and suc fully executed the first ever digital mobile license auction for the provi on o. TM services in Nigeria namely, MTN, M-Tel (which went out of business) and EC owet (now tel). Out of the seven companies that applied for the digital mobile license only ree mentis ned above were qualify upon the payment of two hundred and eighty five $n$ Alion Naira capitalization fee each. This proactive approach by federal government of ria to t telecom sector has made it possible for over 2.5 million Nigerians clutch $\mathrm{M}$ cell or es and handsets today.

Sir arly, he adven of GSM in Nigeria has created the habit of time management and consu phenomenon can be seen from the curtailment of telephone conversations, while an same time eliminate long journey for pleasure and businesses.

Also, Nigy ans are now able to operate their savings, current, mobile money transfer, recharging of GSM, DSTV, searching for old friends whom they have lost contact for years via cell phones or handsets. (Agbasi et al, 2007).

\section{METHOD}

Discussion will be used in this paper throughout which is employed in the analysis of both present and future communications system in Nigeria. 


\section{FIBER OPTICS}

According to Maaki (2004), the idea of fiber optic cable is a fairly new but old technology that was borne in some years back which is designed to be used in data transmission and networking nodes. It is a new technology whereby the cable is made to transmit data that is converted to light pulses. Fiber optics are either made of glass or plastic and conducts light just as copper wire conducts electrons. They are very small in diameters and measure about 6-200 $\mu \mathrm{m}$ (microns). A micron is about $10^{-6} \mathrm{~m}$. The glass or plastic is made of a fiber, often included with a metallic covering to protect it from environmental hazards when buried underomend.

This fiber optics technology is realistic because of the use of lasers. This ca ue tran. data for a long distance without loss of information or what is known as atten tion. Thou very expensive but can carry a huge amount of data over long distance and it is to have very high bandwidth. It was found to be very useful when a laser light, w ich was di ed i to the fiber, remained into it until it emerged at the other end with the sam intens That owed that there was no loss of light as it travelled along the length of the $f$ er. $n$ it is $u$ in data transmission between nodes, a converter is attached to one node which co rts the electrical signals that are emerging from the node into light signals o vel along fiber until a converter at the other node converts it back into the electrica igna it enters the node at the other end. The fiber has advantages over other transmi
efficiency, huge bandwidth and physical tempering.

According to John (2011), a fiber optic cabl Ise light pu"ses to transmit information down lines instead of using electronic pulses to trans informat on down copper lines. Light pulses move easily down the fiber optic line becau principle of "total internal reflection". In this principle, when the angle dence exceeds a critical value, light cannot get out of the glass; instead the light boun es aw. This principle was applied to the construction of fiber optic strand, which made possible to transmit information down fiber lines in the form of light pulses.

\section{OPTICAL FIBERS TOMM ICATION}

Nelkon and Prer (19, in their book title "Advanced level Physics". Light signals can travel along ver fine long glas cbers roughly the same diameter as the human hair. Optical fibers have $y$ aced copper cables previously used in telecommunications. The fiber is a very fine glass of diam er about $125 \mu \mathrm{m}\left(125 \times 10^{-6} \mathrm{~m}\right)$ with a central glass core surrounded by a gl ating ad ang of smaller refractive index than the core.

The ibers e classi a into two main types namely:

(i) Monomode - This fiber has a very narrow core of diameter approximately $5 \mu \mathrm{m}$ $10^{-6} \mathrm{~m}$ ) or less and as such the coating (cladding) is relatively big.

(ii) Multimode - This type of fiber has a core of relatively large diameter that is approximately $50 \mu \mathrm{m}$. In one form of multimode fiber, the core has a constant refractive index $\mathrm{n}_{1}$ such as 1.52 from its center to the boundary with the coating (cladding). The refractive index then changes to a lower value $\mathrm{n}_{2}$ such as 1.48 which remains constant throughout the cladding. This is called a step index multimode fiber since the refractive index 'steps' from 1.52 to 1.48 at the boundary with the cladding. 
(ii) To transmit light signals more efficiently, a multimode fiber is made whose refractive index decreases smoothly from the middle to the outer surface of the fiber. There is no noticeable between the core and cladding. This is called a Graded-Index multimode fiber.
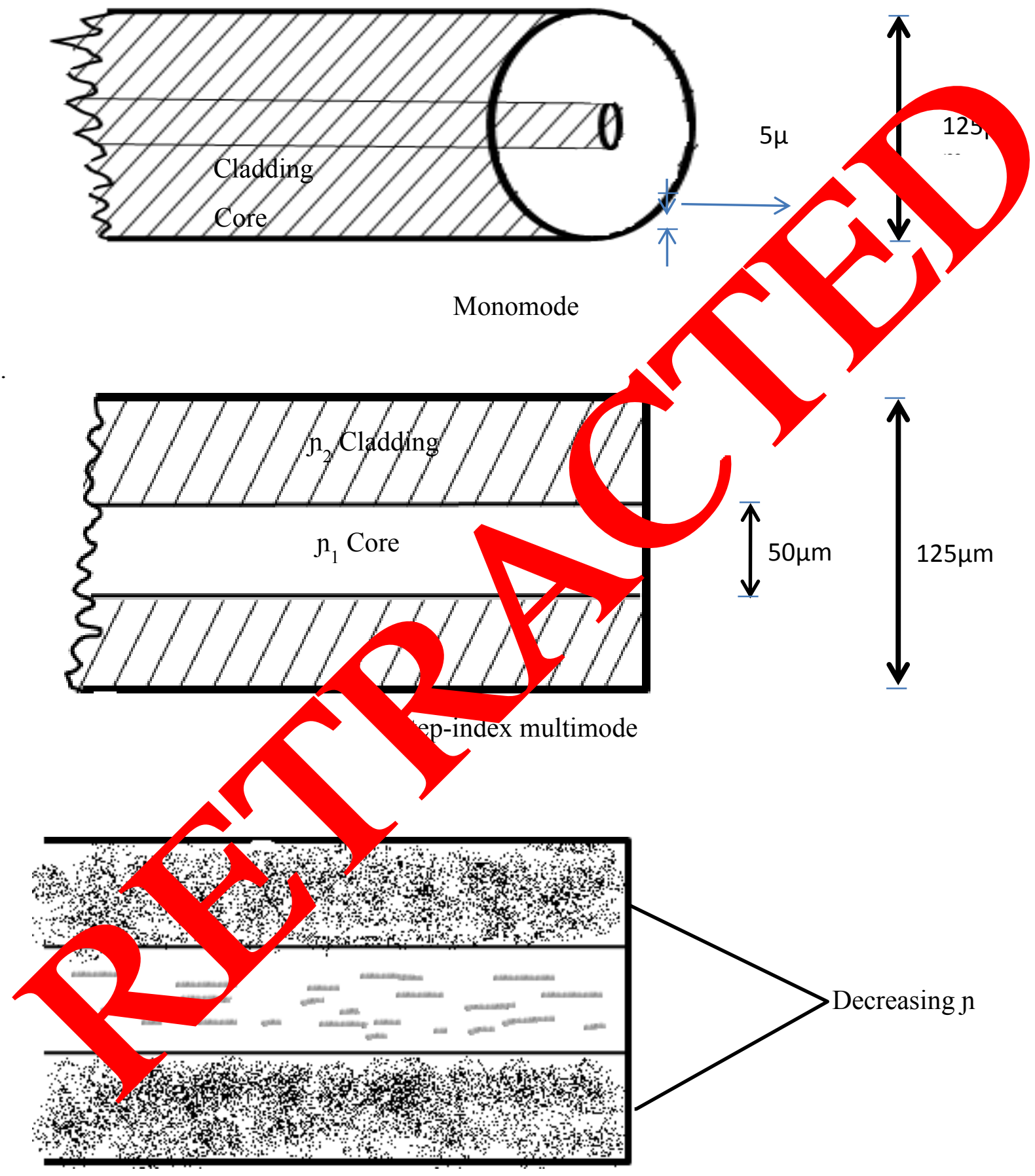

Monomode

Graded-index multimode 


\section{OPTICAL PATHS IN FIBERS}

Let's see what happens when a light signal enters one end of an optical fiber. The figure below shows a step-index fiber. With a large angle of incidence, a ray OA entering one end at $\mathrm{O}$ is refracted into the core along OP and then refracted along PQ in the cladding at Q. In this case, only a very small amount of light, due to reflection, passes along the fiber.

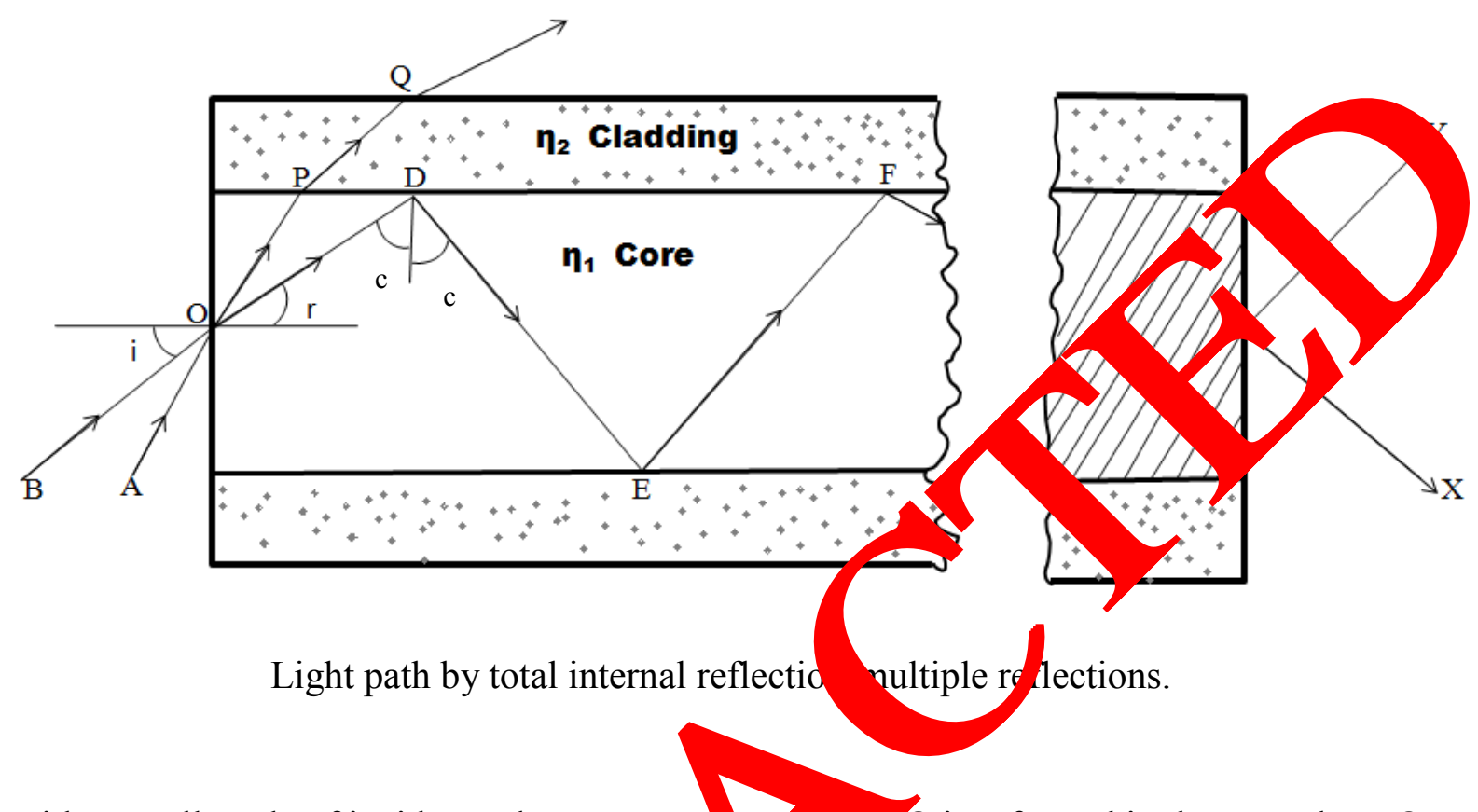

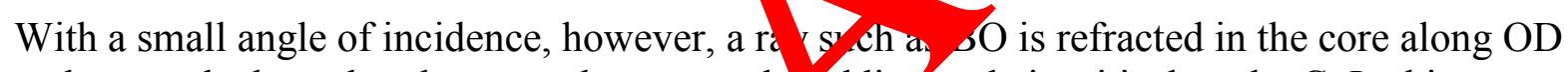
and meets the boundary between th re and o adding at their critical angle, $\mathrm{C}$. In this case, since nsini is constant

$$
\mathrm{n}_{1} \sin \mathrm{C}=\mathrm{n}_{2} \sin \mathrm{C}^{\mathrm{s}} \Rightarrow \mathrm{n}_{2}
$$

where $\mathrm{n}_{1}$ is the core fract index and $\mathrm{n}_{2}$ the slightly smaller cladding refractive index.

Since, $\mathrm{n}_{1}=1.52 \operatorname{san}_{2}=1.48$,

Hence, SinC $/ 1.4=1.4 \times 1.52=0.974$

$\mathrm{C} \approx 77^{\circ}$

The $\mathrm{v}$ OD is row totally reflected at D along DE, where it again meets the core-cladding boun at ical angle. At E, therefore, it is totally reflected along EF.

In this w by total internal reflection, a ray of light entering one end of a fiber can travel along the fiber by nultiple reflections with a fairly high light intensity. At the other end of the fiber, the ray emerges in a direction $\mathrm{X}$ (odd number of multiple reflections) or a direction $\mathrm{Y}$ (even number of multiple reflections).

\section{DISCUSSION}

So far we have seen that optical fiber has thin glass core coated by glass of smaller refractive index which make total internal reflections occurring repeatedly at the interface of 
the glasses all along the fiber. Telecommunication industries took advantages of the fact that light in glass travels faster than electrical signals in copper cable, more messages per cable length can be sent and clearer sound can be heard to employ and deploy optical fiber to boost their business activities.

\section{OPTICAL FIBER VIEWING SYSTEMS}

Even though optical fibers have found their main application in hich-sneed communications, they are also used to make remote viewing systems for medical and or purposes where access to the scene is restricted. The idea is that very large bers of $t_{1}$ fibers are packed together to form a flexible bundle: one end is placed in con thet wh the scer the other end forms a remote image of the scene which may be around a orner or on of er side of the small aperture. Each individual fiber transmits light along lengt) com th ocene to the viewer. Individual fiber is incapable of forming an image: the $\mathrm{m}$ collect ght from a small area of the scene and transmit it to the viewer. However, s' ice each 'see, a slightly different part of the scene, they collectively transmit an imag the scen the viewer. It is important to ensure that the fibers do not change their rela e pos ns over the length of the bundle; otherwise the image will be scrambled at and will be totally unintelligible. Small bundles of fibers need not be $\mathrm{m}$ ch larger than a bypodermic needle, and can easily be inserted without pain into a patient. $\mathrm{P}$ of the buncle carries illumination from the outside, while the other part transmits the image. ing such +chniques, 'keyhole' surgery can be performed, without the need for any major incis

\section{FOCUS ON THE FINDING}

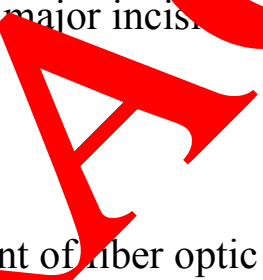

The finding focus is on aplo ment of iber optic infrastructure as the most effective and efficient reliable tool fo various nodes on the internet.

\section{CONCLUSIOY}

The inter et has been do abed as the greatest invention of man after the industrial revolution. $T$ is rev tionary marvel has been made possible by satellite and microwave communication s M'bo -former UNESCO scribe rightly pointed out over a decade ago, "inform tech opy as opened up such tremendous vistas for modern societies that any faily e to i ster it a ald mean a life of permanent insubordination". The technology among ond hay of other techniques to give or to refuse access to a whole range cientitic data and knowledge and thus to design new models of development.

Joh our new international information society in Nigeria is plagued with several bottlenecks such as the absence of information technology infrastructures like optical fiber backbone, weak telecommunications backbone, and epileptic power supply.

\section{Recommendations}

(i) Nigeria has to urgently overhaul the existing copper cable and wireless networks and replace them with well-structured underground cabling manhole ducts to take care of fiber systems and future expansions. 
(ii) Developed National information super highway infrastructure base on a nationwide fiber backbone linked to Africa on fiber network for fast and easy link to the rest of the world.

(iii) Encourage foreign investors to establish an industry that will manufacture optic fiber cable locally in order to reduce the cost of purchasing, transportation and installation which in turn reduce the cost of service provision that will negatively affects the end users.

It is pertinent at this junction to point out that Monomode optic fiber infrastructure is the best communication tool that should urgently be employed and deployed in Nigeria in order to boost and overcome the problems of network connectivity experienced over the though it is more expensive than multimode optic fiber, it gives a higher transy ission rat of up to fifty-times more than multimode. This is because the small core and sin. light-wa virtually eliminate any distortion that could result from overlapping lis puls there providing the least signal attenuation which is the highest transmission s eed of any th able type.

Though, multimode fiber gives a high bandwidth at higb distances than monomode; but by virtue of the fact that light $y$ es (laser) $d$ spersed into numerous paths as they travel through the cable's core $p$ akes typically 0 cause signal distortion at the receiving end, thereby resulting in an uncl ind in plete data transmission as is the case with wireless services we have today i Nigeria. Hence, ew monomode optic fiber cable should be designed to use Gigabyte and $b$ yond.

\section{References}

[1] Agbasi, K.C; Nnebbe, S.E; Onyejegbu, L. T. hd M modu, J.B. (2007), "GSM operation in Nigeria”. Conference proce so Ni ria computer society, vol. 18. Pp. 179-188.

[2] John Machesney (2011), "Cer O lics" Ret _eved 15 ${ }^{\text {th }}$ December, 2011 from $\mathrm{http} / / \mathrm{www}$. arcelect.co

[3] Maaki, P.T. (2004 roduction amputers and basic programming. First published by oracle busine Lta nting press, Makurdi 35-36 pp. ISBN 978-37031-2-9.

[4] Margolis, M ana Resnick, 1999), Third voice: vox populi vox Dei? First Monday, vol. 4. No. 10 Octob a at http/www.firstmonday.org/issues/issue4-10/Margolis/

[5] Nelkon, M Parker . (1995), Advanced level physics seventh editon. Published by CD blishe nd astributors. 11, daryaganj, New delhi-110002 (India) 440-445 pp.

[6] Guag O.E. (2002), Internet and satellite communication networks being leture a ren.mal ational workshop on communications organized by erosion

tele 2002 à he civic centre hall of River state government, Port Harcourt.

[7] Prince Osuagwu (2011), "How NigComsat-1R will impact Nigerian economy" Retrieved $27^{\text {th }}$ December, 2011 from http//www.vanguardng.com/2011/12/how-nigComsat-1R will impact-nigerian economy.

[8] Winston, B. (1998), Media technology and society: A history from the telegraph to the internet. New York Routledge. 
[9] Liverpool E. Onyije, Jacinta A. Opara, International Letters of Social and Humanistic Sciences 1 (2014) 81-87.

[10] Azuh Oluchi Jannet, Melody Ndidi Modebelu, International Letters of Social and Humanistic Sciences 2 (2014) 88-96.

[11] Elijah Akwarandu Njoku, Patrick Etim Akpan, International Letters of Social and Humanistic Sciences 4 (2014) 22-30.

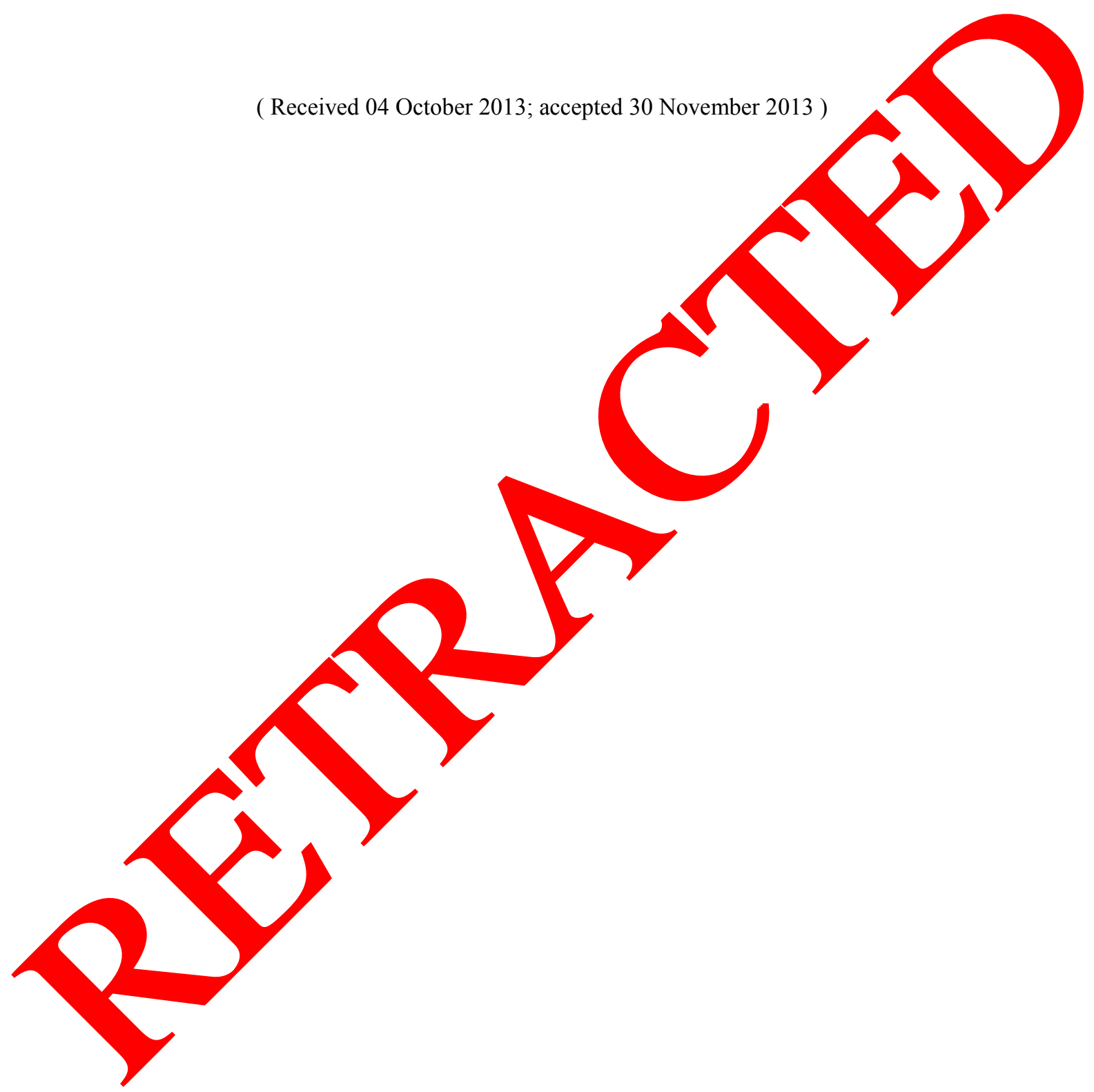

